\title{
Mixing Patterns and Residence Time Determination in a Bubbling Fluidized Bed System
}

\author{
A. E. Ghaly and K. N. MacDonald \\ Department of Process Engineering and Applied Science, \\ Faculty of Engineering, Dalhousie University, Halifax Canada \\ Email: abdel.ghaly@dal.ca
}

Received 2012-07-31, Revised 2012-08-15; Accepted 2012-08-15

\begin{abstract}
Fluidized bed gasification can be used to convert the solar energy stored as carboneous compounds in biomass into a carbon neutral fuel with reduced emissions. Canada produces 20.57 million tonnes of wheat straw annually which could be used for green energy production. Wheat straw residue gasification has the capability of replacing $7.5 \%(0.62 \mathrm{EJ})$ of Canada's annual fossil fuel consumption. To achieve efficient gasification in a fluidized bed proper fuel mixing and residence time must be achieved. The aim of this study was to investigate the effects of sand particle size, distributor plate shape and angle, bed height and fluidizing velocity on particle mixing and residence time in the fluidized bed reactor. Greater values of the residence time were obtained with course sand whereas lower values were obtained with fine sand. An increase in the angle of convex or a decrease in the angle of a concave of the distributor plate resulted in an increase in the residence time. Both the concave and convex distributor plates achieved vertical upward and downward movements of the bed material resulting in continuous bed material turnover and, thus, good mixing. However, the concave plate achieved longer residence time which will result in better conversion efficiency. To improve the mixing properties of the binary mixture, which has great tendency for segregation due to density differences, an angled distributor plate (concave or convex) should be used. Considerable increases in the residence time were recorded with increases in the bed height. Increasing the fluidizing velocity decreased the residence time due to the increase in the bubble velocity. However, since the conversion efficiency is affected by the degree of mixing, it will also be improved by increasing the fluidization velocity. A velocity above $1.50 \mathrm{U}_{\mathrm{mf}}$ is recommended for better fluidization and improved mixing.
\end{abstract}

Keywords: Biomass; Gasification, Straw, Bed Height; Distributor Plate, Velocity

\section{INTRODUCTION}

Agricultural residues can be converted into valuable fuel products, thereby increasing the profits of crop production for farmers (Naik et al., 2010). The solar energy converted in biomass materials into chemical energy and trapped in the form of organic carbon can be converted into heat and gas through combustion and gasification. The organic carbon formed within the biomass during photosynthesis is released during combustion, making the biomass a carbon neutral energy source (Surisetty et al., 2012; Goyal et al., 2008). The conversion of biomass into usable energy sources represents a vital method of reducing fossil fuel dependence and greenhouse gas emission. The low levels of impurities in biomass lead to lower $\mathrm{SO}_{\mathrm{x}}$ and $\mathrm{NO}_{\mathrm{x}}$ emission during combustion and thus reduced contribution to acid rain (Wood and Layzell, 2003).

Wheat is harvested in Canada on 10.95 million hectares of land annually, in the provinces of Manitoba, Saskatchewan, and Alberta (Wood and Layzell, 2003). Wheat grain composes only $50 \%$ of the harvested crop, with the remaining balance made up of straw and chaff (McCartney et al., 2006). With 20.57 million tonnes of wheat harvested annually, Canadian farmers also produce 20.57 million tonnes of wheat crop residue which must be disposed of (Wood and Layzell, 2003). 
Wheat straw produced has long been used on the farm as a form of animal bedding, crop cover and animal feed. However, straw use as animal feed is limited due to the low digestibility of wheat varieties breed for tougher stalks to reduce lodging (McCartney et al., 2006). More recently wheat straw has been recognised as a valuable form of biomass providing a source of renewable energy and thus generating additional profit for the farmers (Naik et al., 2010). Cereal straw gasification has proven an efficient method of producing fuel from wheat straw (Zeng et al., 2007; Ergudenler and Ghaly, 1992). Gasification of cereal straw could be used to convert 20.57 million tonnes of wheat residue into $0.62 \mathrm{EJ} /$ year of energy annually in Canada, or the equivalent of 14.7 million tonnes of oil (Wood and Layzell, 2003). As Canada's annual fossil fuel consumption amounts to $8.24 \mathrm{EJ}$, wheat crop residues could alone could replace $7.5 \%$ of the fossil fuel consumed in Canada (Surisetty et al., 2012).

The application of fluidized bed gasification technology to cereal straws is increasing rapidly (Ergudenler and Ghaly, 1992; Khan et al., 2009). Effective gasification of straw requires rapid mixing of the fuel material with the inert sand of the bed in order to obtain a uniform distribution of the fuel particles, a better chemical conversion and a uniform temperature throughout the bed (Rowe and Nienow, 1976; Mansaray and Ghaly, 1999; Surisetty et al., 2012). However, mixing problems in fluidized bed systems become very severe when fuel particles vary both in size and density resulting in material segregation (Yoshida et al., 1980; Ergudenler and Ghaly, 1992; Nemtsow and Zabaniotou, 2008). One of the main causes of segregation is the out of balance forces arising during the periodic disturbances associated with the passage of the bubbles due to differences in density (Nienow et al., 1978; Nemtsow and Zabaniotou, 2008).

The gas distributor is one of the most critical features in the design of a fluidized bed reactor (Ergudenler and Ghaly, 1992). The use of a suitable gas distributor is essential for satisfactory performance of gas-solid fluidized beds (Sathiyamoorthy and Sridhar, 1979). Understanding of solids mixing and flow characteristics of gases and solids near the grid region of a fluidized bed reactor is vitally important from the standpoint of design and scale up of gas distribution systems (Werther, 1978; Bonniol et al., 2009). The presence of stagnant zones near the grid region can cause hot spots resulting in agglomeration and eventual reactor failure (Ergudenler and Ghaly, 1993).

\section{OBJECTIVES}

The objectives of the study were: (a) to determine the effects of sand particle size, type of distributor plate, bed height and fluidization gas velocity on the fuel residence time using tracer particles having equivalent density and diameter to those of the straw particles and (b) to investigate the mixing patterns in a bubbling fluidized bed system at room temperature using high speed photography.

\section{EXPERIMENTAL APPARATUS}

The experimental apparatus used in this study is shown in Fig. 1. The main components are a fluidized bed reactor, an air supply system and a cyclone.

\subsection{Fluidized Bed Reactor}

The fluidized bed reactor consisted of: a support stand, a conical inlet section, a distributor plate, a fluidizing column, a mechanical injector, a disengagement section and an outlet duct.

The support stand was constructed of $38 \mathrm{~mm}$ mild steel angle iron. An angle iron horizontal square structure $(380 \mathrm{~mm})$ was supported by four $475 \mathrm{~mm}$ long legs inclined at $15^{\circ}$ from vertical for stability. Five $8 \mathrm{~mm}$ x $30 \mathrm{~mm}$ hex head bolts were used to fix the inlet of the fluidized bed to the support stand.

The vertical section of the air line was connected to a funnel shaped $\left(45^{\circ}\right.$ from the vertical) inlet section made of $(3.2 \mathrm{~mm}$ thick, $120 \mathrm{~mm}$ height and $63 \mathrm{~cm}$ bottom diameter and $255 \mathrm{~mm}$ top diameter) stainless steel material. A flange made of $8 \mathrm{~mm}$ thick stainless steel (255 and $355 \mathrm{~mm}$ inner and outer diameter, respectively) was welded to the upper portion of the funnel. A thick rubber gasket of $3 \mathrm{~mm}$ thickness was used between the flanges of the conical inlet section and the distributor plate to provide good sealing.

The distributor plate was made of $8 \mathrm{~mm}$ thick circular steel plate of $355 \mathrm{~mm}$ diameter. A circular area of $220 \mathrm{~mm}$ diameter $(1.63 \%$ of the bed cross sectional area) was perforated. A total of 267 holes of $2 \mathrm{~mm}$ diameter each were drilled in the circular plate in the form of rings starting from the center with a pitch of 11.1 $\mathrm{mm}$. A circular screen of 100 mesh size was point welded to the top of the distributor plate. Five plates having exactly the same open area and vertical holes were used $\left(10^{\circ}\right.$ concave, $5^{\circ}$ concave, flat, $5^{\circ}$ convex and $10^{\circ}$ convex). Fig. 2 shows the three types of distributor plates used in this study. 


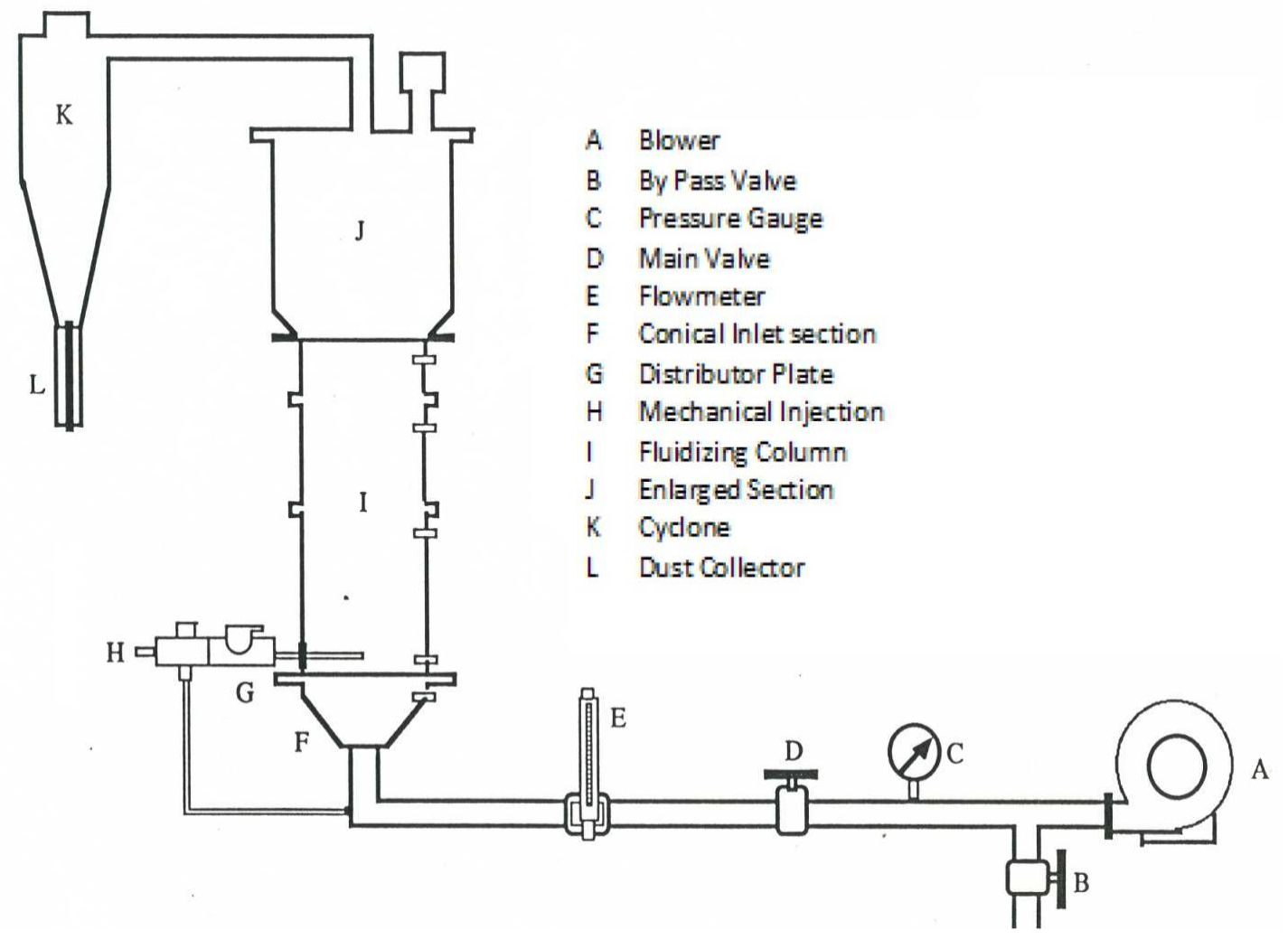

Fig. 1. Experimental apparatus.

The main body of the fluidized bed (fluidising column) was made of a $5 \mathrm{~mm}$ thick plexi glass cylinder (255 $\mathrm{mm}$ inside diameter). It was constructed in three pieces having lengths of $127.5 \mathrm{~mm}, 255.0 \mathrm{~mm}$ and 382.3 $\mathrm{mm}(0.5 \mathrm{D}, 1.0 \mathrm{D}$ and $1.5 \mathrm{D})$, respectively. Two flanges made of $8 \mathrm{~mm}$ thick circular plates were glued to the top and bottom of each cylinder. The height of the fluidizing column was varied by fitting different sections of varying lengths in order to maintain a constant free board height. The sections were bolted to each other and rubber type O-rings of $3 \mathrm{~mm}$ thickness were used between them to provide good sealing. A $55 \mathrm{~mm}$ diameter port was provided near the bottom of the bed to remove the bed material when required.

A specially designed mechanical injector (for the injection of Styrofoam balls) was mounted at the bottom part of the fluidized bed (Fig. 3). In order to avoid the bed material (sand) from flowing through the mechanical injector, an air line (with a pressure level slightly above that of the bed) was connected to the injector. A valve was used to avoid the escape of the Styrofoam balls into the bed before it was injected.
To decrease the rate of elutriation from the top of the fluidized bed, an enlarged section (disengagement section) was used at the upper part of the bed (total height of 395 $\mathrm{cm}$ ). This part was made from $3.2 \mathrm{~mm}$ thick, hot rolled steel. The sides were inclined to $30^{\circ}$ from vertical and the bottom and top diameters were 255 and $350 \mathrm{~mm}$, respectively. The top of the enlarged section was covered with $6 \mathrm{~mm}$ thick hot rolled steel, which was connected to an outlet duct made of $1.6 \mathrm{~mm}$ thick stainless steel material. The vertical section of the duct $(85 \mathrm{~cm} \times 85 \mathrm{~cm})$ was $100 \mathrm{~mm}$ in length whereas the horizontal section $(80$ $\mathrm{cm} \times 40 \mathrm{~cm}$ ) was $400 \mathrm{~mm}$ in length.

\subsection{Air Supply System}

The air supply system consisted of a blower equipped with a filter, a pressure gauge, a main valve, a by-pass valve, an airline, and a flow meter. A blower (Model Engenair R4310A-1- 220 volts and 13.4 amps Engenair, Benton Harbour, MI, USA) having a maximum flow rate of $81.2 \mathrm{~L} / \mathrm{s}(172 \mathrm{cfm})$ and maximum pressure of $2.08 \mathrm{kPa}\left(212 \mathrm{~cm} \mathrm{H}_{2} \mathrm{O}\right)$ was used. 


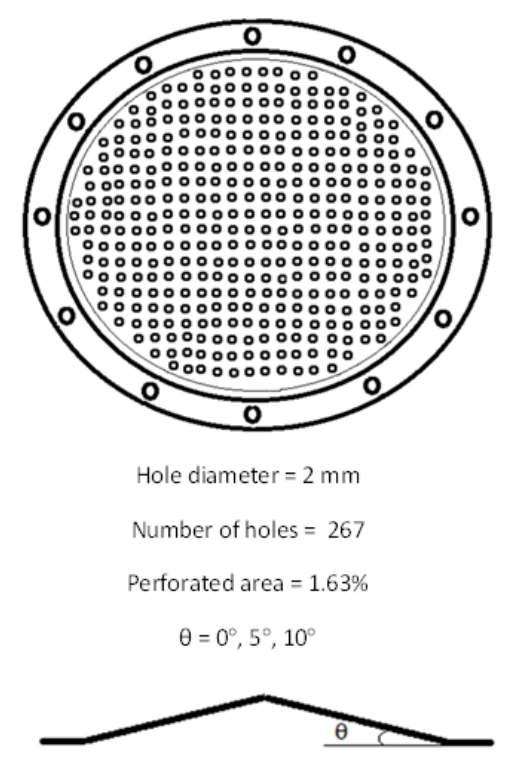

(a) convex

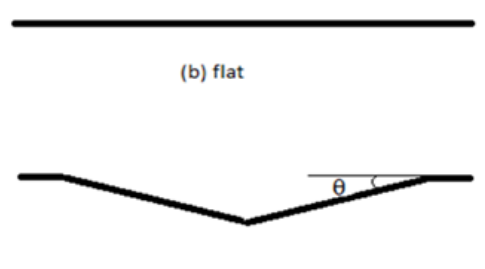

(c) concave

Fig. 2. Types of distributor plates.

It was powered by a $4.8 \mathrm{Hp}, 3$ phase electric motor (Blador Industrial Motor, Fort Smith, AK, USA) and ran at a speed of $2850 \mathrm{rpm}$. A filter having a micron rating of 25 and a maximum flow of $7.08 \mathrm{~m}^{3} / \mathrm{min}$ (Model Number 34225211, Cole Parmer Canada Inc., Montreal, Quebec, Canada) was used at the blower inlet to filter the incoming air in order to supply dust and water free air to the fluidized bed reactor.

A pressure gauge (USG, Ametek, Horsham, PA, USA), having a pressure range of $0-690 \mathrm{kPa}$ with a scale of $13.8 \mathrm{kPa}$ increments, was used at the exit of the blower to maintain atmospheric pressure in the bed. The main valve was used to control the air flow rate while the by-pass valve was used to by-pass the excess air to avoid over heating of the motor. The air line was composed of horizontal and vertical steel pipe sections. The horizontal section on which the flow meter (Metal FLT-type, Cole Parmar Catalog No. N03251-60, Chicago, IL) was mounted was connected to a $600 \mathrm{~mm}$ long horizontal steel pipe having an inner diameter of $63 \mathrm{~mm}$.

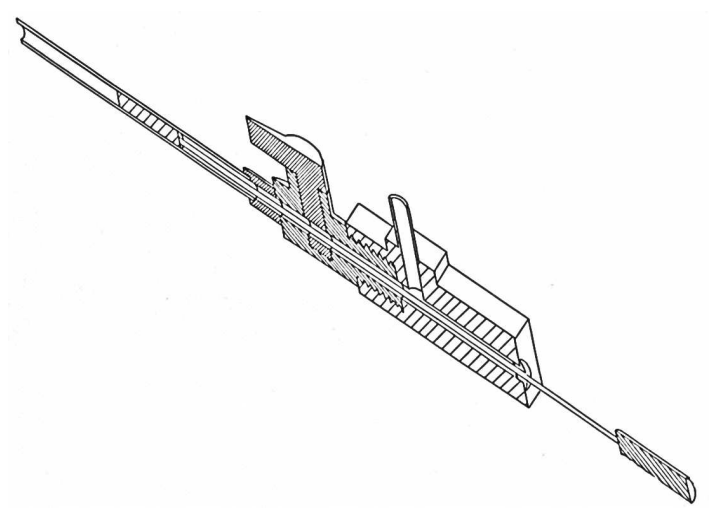

Fig. 3. Mechanical injector.

This was connected to a $100 \mathrm{~mm}$ long vertical pipe by a $90^{\circ}$ elbow having the same inner diameter. The flow rate of the fluidizing air was measured using there "Flow Cell Bypass Flowmeters" (1035 kPa) with different ranges 2.4-11.8, 5.6-25.5 and 11.8-51.9 L/s, depending on the required air flow rate $(3.52 \mathrm{~L} / \mathrm{s}-43.61 \mathrm{~L} / \mathrm{s})$. Each flow meter was installed in a horizontal pipe having the same flow meter size rating. The length of the pipe section downstream the flow meter was kept greater than three times the diameter of the pipe where was that upstream of the flow meter (after the valve) was greater than eight times the diameter of the pipe.

\subsection{Cyclone}

A cyclone connected to the outlet duct was used to capture the fine solid particles escaping from the top of the bed. It was made from a $2 \mathrm{~mm}$ thick stainless steel metal sheet and consisted of two sections: a conical section (300 mm height and it's sides inclined at 10 from vertical) and a cylindrical section (150 $\mathrm{mm}$ diameter and $300 \mathrm{~mm}$ height). A gas outlet pipe of $75 \mathrm{~mm}$ diameter was extended $90 \mathrm{~mm}$ axially into the cyclone. The fine dust particles were collected in a cylindrical plexi-glass dust collector (60 mm diameter and $200 \mathrm{~mm}$ height).

\section{EXPERIMENTAL PROCEDURE}

\subsection{Experimental Design}

The effects of five parameters (Table 1) on the fuel particle residence time and mixing pattern were investigated. These were: (a) the sand particle size with two levels, (b) the distributor plate angle with five levels, (c) the bed height with four levels, (d) the fluidizing velocity with five levels, and (e) the injection distance (the radial distance from the wall) with two levels. Six measurements were 
taken during each experimental run which resulted in 400 experimental runs and 2400 measurements.

\subsection{Styrofoam Ball Selection and Preparation}

Five samples of Styrofoam balls (each containing 400 balls of same diameter) were weighed. The volume of each Styrofoam ball was calculated. The average volume and density of each sample were estimated.

Five samples of chopped straw (each containing 400 pieces of different sizes) were weighed. The volume of a Styrofoam ball equivalent to that of the straw was found by dividing the average weight of the straw by the average density of the Styrofoam ball. Then, the average diameter of straw equivalent to that of the Styrofoam ball was calculated.

Six dye colors were used to color the Styrofoam balls. The color difference of balls was used to distinguish between the previously injected Styrofoam balls, which have already appeared at the end surface during the data collection period and the new one which has just been injected.

Table 1. Experimental Parameters.

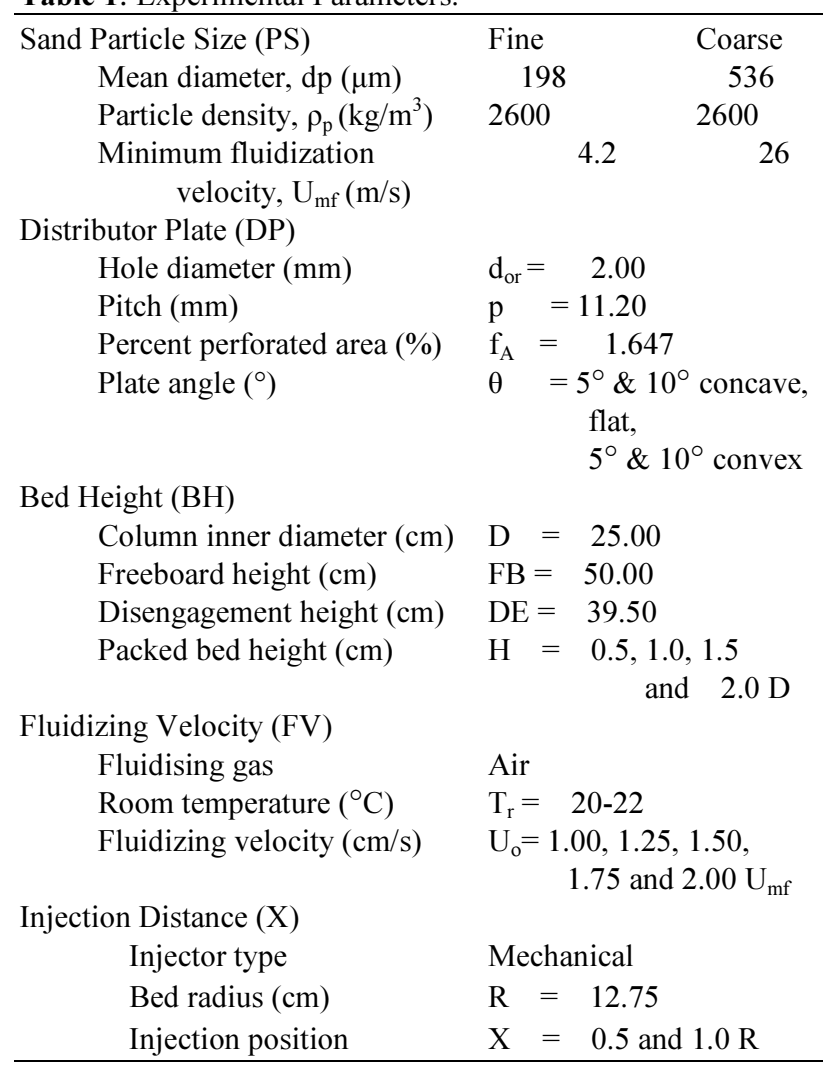

\subsection{Determination of Sand Particle Size Distribution}

The most common method used to measure the size of irregular particles larger than $75 \mu \mathrm{m}$ is sieving (Geldart, 1986). Sieving operation was performed for both types of the sand used in the study using American Standard Sieves. After sieving the mean sizes of the particles was determined using the following equation:

$d_{p}=\frac{1}{x_{i} / d_{p 1}}$

Where:

$\mathrm{d}_{\mathrm{p}}=$ Mean size of the particles $(\mu \mathrm{m})$

$\mathrm{x}_{\mathrm{i}}=$ Weight fraction of powder of size $\mathrm{d}_{\mathrm{pi}}(\%)$

$\mathrm{d}_{\mathrm{pi}}=$ Mean sieve size $(\mu \mathrm{m})$

The particle size distributions of the fine and coarse sands are given in Table 2 and Fig. 4.

\subsection{Determination the Minimum Fluidizing Velocity}

The minimum fluidizing velocity was calculated using the following equation (Ergudenler et al., 1997):

$$
\mathrm{U}_{\mathrm{mf}}=\frac{\mu_{\mathrm{g}}}{\rho_{\mathrm{p}} \mathrm{d}_{\mathrm{p}}}\left[\mathrm{C}_{1}^{2}+\mathrm{C}_{2} \mathrm{Ar}\right]^{0.5}-\mathrm{C}_{1}
$$

Where:

$\mu_{\mathrm{g}}=$ Viscosity of the fluidizing gas $(\mathrm{g} / \mathrm{cm} \mathrm{s})$

$\rho_{\mathrm{g}}=$ Density of the fluidizing gas $\left(\mathrm{g} / \mathrm{cm}^{3}\right)$

$\rho_{\mathrm{p}}=$ Density of the sand particle $\left(\mathrm{g} / \mathrm{cm}^{3}\right)$

$\mathrm{C}_{1}=27.2$

$\mathrm{C}_{2}=0.0408$

$\mathrm{A}_{\mathrm{r}}$ can be calculated as follows (Gibilaro, 2001):

$$
A_{r}=\frac{\rho_{g} d_{p}^{s}\left(\rho_{p}-\rho_{g}\right) g}{\mu_{g}{ }^{2}}
$$

\begin{tabular}{|c|c|c|c|c|}
\hline \multicolumn{2}{|c|}{ Sieve aperture $(\mu \mathrm{m})$} & \multirow[b]{2}{*}{$\begin{array}{l}\mathrm{d}_{\mathrm{pi}} \\
(\mu \mathrm{m})\end{array}$} & \multicolumn{2}{|c|}{ Weight Fraction (\%) } \\
\hline Minimum & Maximum & & Fine & Coarse \\
\hline 850 & 1410 & 1130 & 0.00 & 0.77 \\
\hline 595 & 850 & 723 & 1.28 & 34.50 \\
\hline 425 & 595 & 510 & 19.95 & 57.40 \\
\hline 297 & 425 & 361 & 23.36 & 5.85 \\
\hline 212 & 297 & 254 & 22.57 & 0.82 \\
\hline 0 & 212 & 201 & 32.84 & 0.66 \\
\hline $\begin{array}{l}\mathrm{d}_{\mathrm{p}}=\text { mean } \\
\mathrm{d}_{\mathrm{p}}=198 \mu \\
\mathrm{d}_{\mathrm{p}}=536 \mu \\
\mathrm{d}_{\mathrm{pi}}=\text { mean }\end{array}$ & $\begin{array}{l}\text { ticle size } \\
\text { or fine san } \\
\text { or coarse } s \\
\text { ve size }(\mu \mathrm{n}\end{array}$ & & & \\
\hline
\end{tabular}

Table 2. Sand Particle Size 


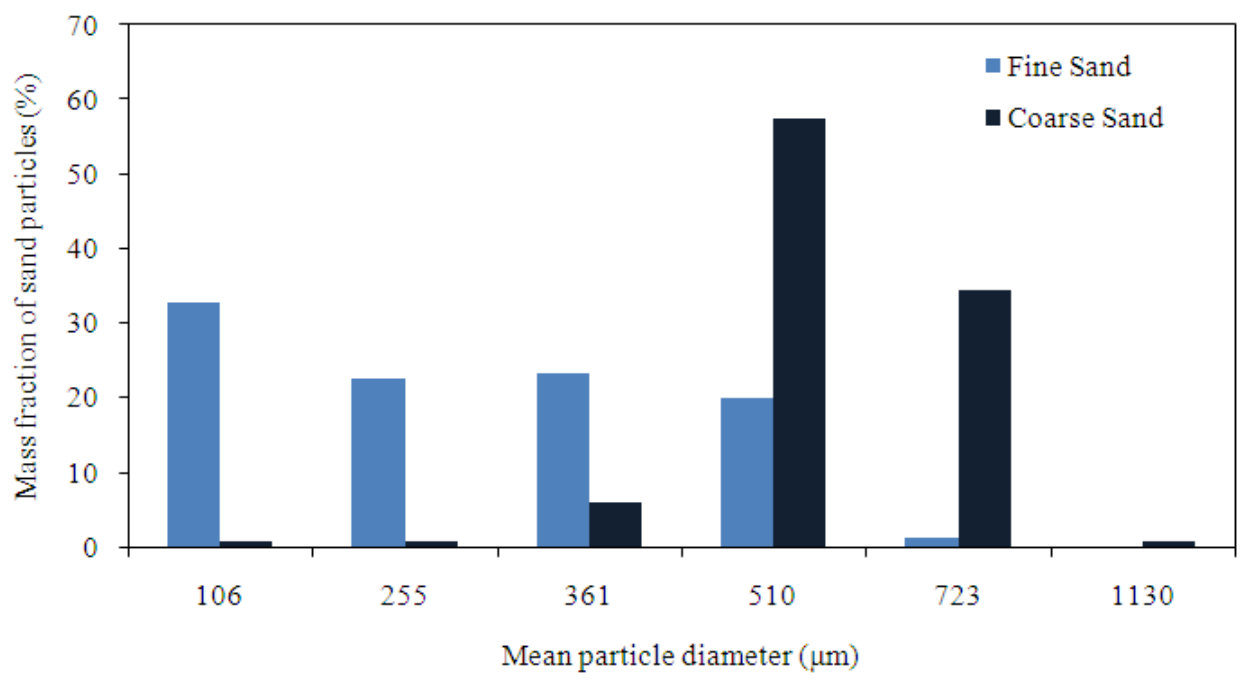

Fig. 4. Sand particle size distribution.

\subsection{Experimental Protocol}

The selected distributor plate was put in place and the fluidizing column was assembled. One type of sand was placed in the reactor up to the required bed height. The blower was turned on and the flow rate was adjusted until the required fluidizing velocity was obtained. The mechanical injector used to inject the Styrofoam balls was adjusted to the center of the reactor. The injector was then used to inject the Styrofoam balls at the center of the bed and the time required for the ball to travel from the bottom of the bed to the surface was measured using an electronic stop watch. This was repeated six times using various colored Styrofoam balls. The procedure was repeated until six measurements each were taken for all flow rate-bed height combinations. The tip of the mechanical injector was then positioned half way between the reactor wall and the center of the fluidizing column and the procedure was repeated until six measurements each were obtained with all flow ratebed height combinations. Then, the sand was changed and the above experiments were repeated with the other type of sand. The entire procedure was repeated with the five distributor plates.

High speed photography was used during the experimental runs in order to gain a better understanding of the mixing and fluidising processes. The films were analyzed on a photo optical analyzer. This unit allowed a frame by frame observation of the films and consequently gave a good picture of the sand and air bubble movement.

\section{RESULTS AND DISCUSSIONS}

\subsection{Mixing}

When the Styrofoam balls were injected from the bottom of the fluidizing bed, they moved upward in the bed until they reached the surface of the sand. Vertical transport and mixing of particles were achieved by bubble motion. Each bubble carried a wake of particles which was ultimately deposited on the bed surface (Fig. 5.). It caused a drift of particles to be drawn up as a spout below it as it left the bed of sand. Muller et al. (2007) used particle image velocimetry capture the radial mixing that occurs during bubble burst as shown in Fig. 6.

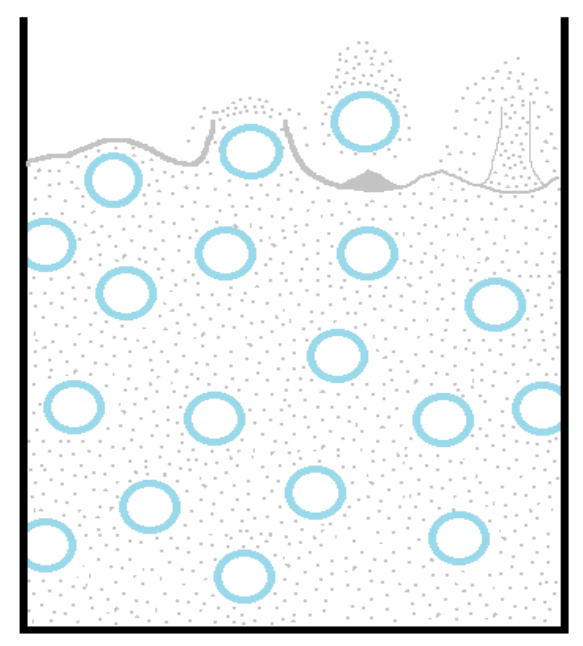

Fig. 5. Bubble ejection stages. 
The analysis of the high speed films indicated that the shape (concave, convex or flat) and the angle of the distributor affected the vertical and localized mixing as well as the upward/downward movement of sand particles (Fig. 7). With the convex distributor plate, there was an observed upward movement of the sand particles at the center of the fluidizing column and a downward movement close to the wall of the fluidizing column. These resulted in a complete bed material turn over in addition to the localized mixing caused by the bubbles movement. The surface of the expanded bed material took a convex shape and the degree of curvature was affected by the distributor plate angle. When using the concave distributor plate the upward movement was observed beside the walls of the fluidizing column whereas the downward movement was observed at the center which also resulted in a complete bed material turn over. The surface of the expanded bed material took a concave shape and the degree of curvature was also affected by distributor plate angle of concave. The flat distributor plate achieved good fluidization and a uniform bed material expansion. Localized mixing caused by the upward movement of the bubbles was clearly evident but no bed material turnover was observed.

Stein et al. (2000) observed the particles rising near the center of the bed and falling near the walls when using a flat distributor plate and beds with an aspect ratio $>1(\mathrm{BH}>\mathrm{D})$. This pattern was created as the rapidly rising sand was carried through the bubble wake, then ejected radially as the bubbles burst at the surface.

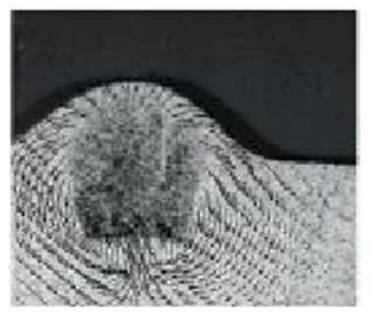

(a) Bubble rises to the surface

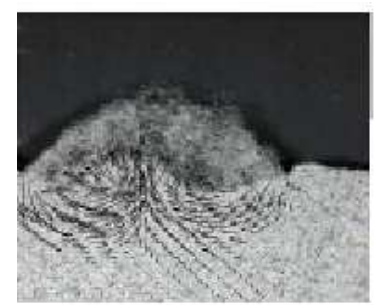

(c) Bubble wake is ejected from the surface

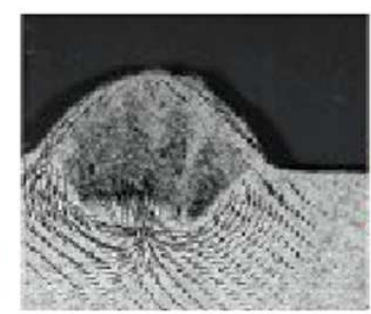

(b) Bubble roof breaks down as the bubble erupts

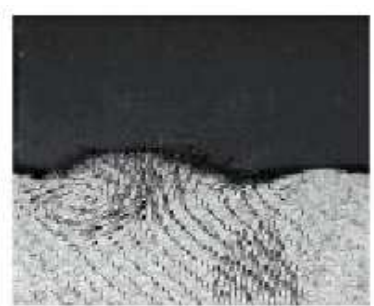

(d) Wake falls and the surface settles
Fig. 6. Bubble wake ejection (Muller et al., 2007)
The ejected particles carried less momentum and were pushed towards the sides. New bubbles continue to burst. The buildup of nearly stagnant sand begins to fall as the bed begins to circulate. Increasing fluidization velocity and bed height increased mixing and decreased residence time. Bed material turnover was reported (at low frequencies of $<0.5 \mathrm{~Hz}$ ) at high fluidization velocity.

Chyang et al. (2008) studied the effect of distributor design on the mixing of fluidized beds and observed low mixing and turn over with flat perforated plates. Axial mixing occurred primarily in the bubble wake at the surface of the bed material. The angled distributors allowed for better axial mixing and turnover by imparting axial momentum on the fluidizing gas. In all distributor arrangements studied, mixing increased with increased fluidizing gas velocity.

Muller et al. (2007) reported that particle velocity was primarily axial during bubble rise in all regions other than the wake. Wake ejection represented the only phase of bubble bursting in which high vorticity and radial mixing was observed.

\subsection{Residence Time}

With a low bed height $(0.5-1.0 \mathrm{D})$ and a high fluidizing velocity $\left(1.75-2.00 \mathrm{U}_{\mathrm{mf}}\right)$, it was not possible to measure the residence time with the technique used in this study. Bigger bubbles were observed which erupted at the surface making it difficult to see the Styrofoam balls at the time when they reached the surface. On the other hand, with higher bed heights $(1.5-2.0 \mathrm{D})$ and lower fluidizing velocities $\left(1.00-1.25 \mathrm{U}_{\mathrm{mf}}\right)$, it was not possible for the Styrofoam balls to reach the surface of the bed as fluidization was not achieved. Therefore, statistical analysis of the whole experimental data (2400 measurements) was not possible due to these missing measurements. Thus, three levels of fluidizing velocity $\left(1.00,1.25\right.$ and $\left.2.0 \mathrm{U}_{\mathrm{mf}}\right)$ were eliminated and analysis of variance was then performed on 960 measurements, as shown in Table 3. In order to test the differences among the levels of each of the variables, Duncan Multiple Range Test was carried out on the data. The results are shown in Table 4.
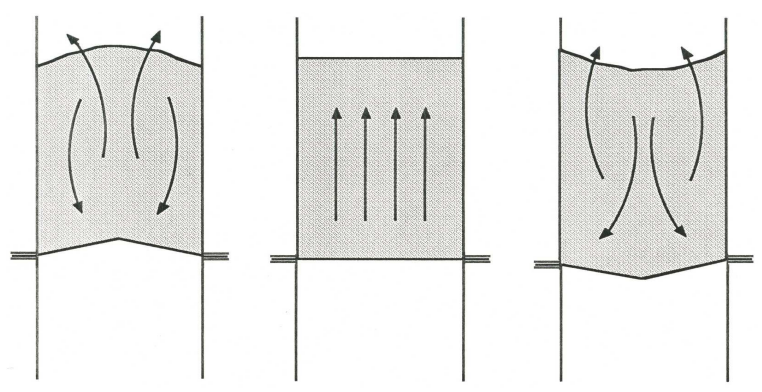

Fig. 7. Effect of distributor plate on the mixing patterns in a bubbling fluidized bed 
Table 3. Analysis of variance.

\begin{tabular}{|c|c|c|c|c|c|}
\hline Source & DF & $\mathrm{SS}$ & MS & $\mathrm{F}$ & $\mathrm{PR}>\mathrm{F}$ \\
\hline Total & 959 & 3332.47 & & & \\
\hline Model & 159 & 2141.24 & 13.47 & 56.34 & 0.0001 \\
\hline PS & 1 & 58.09 & 58.09 & 243.00 & 0.0001 \\
\hline DP & 4 & 210.78 & 52.70 & 220.44 & 0.0001 \\
\hline $\mathrm{BH}$ & 3 & 1306.55 & 435.52 & 1821.96 & 0.0001 \\
\hline FV & 1 & 87.89 & 87.89 & 367.70 & 0.0001 \\
\hline $\mathrm{X}$ & 1 & 0.02 & 0.02 & 0.07 & 0.7867 \\
\hline PS*DP & 4 & 91.47 & 22.87 & 95.66 & 0.0001 \\
\hline PS*BH & 3 & 25.38 & 8.46 & 35.39 & 0.0001 \\
\hline PS*FV & 1 & 9.20 & 9.20 & 38.49 & 0.0001 \\
\hline PS*X & 1 & 1.05 & 1.05 & 4.41 & 0.0361 \\
\hline $\mathrm{DP} * \mathrm{BH}$ & 12 & 66.12 & 5.51 & 23.05 & 0.0000 \\
\hline $\mathrm{DP} * \mathrm{FV}$ & 4 & 9.82 & 2.46 & 10.27 & 0.0001 \\
\hline $\mathrm{DP} * \mathrm{X}$ & 4 & 4.85 & 1.21 & 5.07 & 0.0005 \\
\hline $\mathrm{BH}^{*} \mathrm{FV}$ & 3 & 43.42 & 14.47 & 60.55 & 0.0001 \\
\hline $\mathrm{BH}^{*} \mathrm{X}$ & 3 & 5.39 & 1.80 & 7.52 & 0.0001 \\
\hline $\mathrm{FV} * \mathrm{X}$ & 1 & 0.67 & 0.67 & 2.82 & 0.0937 \\
\hline $\mathrm{PS} * \mathrm{DP} * \mathrm{BH}$ & 12 & 123.23 & 10.27 & 42.96 & 0.0000 \\
\hline $\mathrm{PS} * \mathrm{DP} * \mathrm{FV}$ & 4 & 2.95 & 0.74 & 3.09 & 0.0154 \\
\hline $\mathrm{PS} * \mathrm{DP} * \mathrm{X}$ & 4 & 1.50 & 1.50 & 1.57 & 0.1805 \\
\hline $\mathrm{PS} * \mathrm{BH} * \mathrm{FV}$ & 3 & 13.06 & 4.35 & 18.21 & 0.0001 \\
\hline $\mathrm{PS} * \mathrm{BH} * \mathrm{X}$ & 3 & 0.22 & 0.07 & 0.30 & 0.8243 \\
\hline $\mathrm{PS} * \mathrm{FV} * \mathrm{X}$ & 1 & 0.0004 & 0.0004 & 0.00 & 0.9663 \\
\hline $\mathrm{DP} * \mathrm{BH} * \mathrm{FV}$ & 12 & 15.56 & 1.30 & 5.43 & 0.0001 \\
\hline $\mathrm{DP} * \mathrm{BH}^{*} \mathrm{X}$ & 12 & 9.84 & 0.82 & 3.43 & 0.0001 \\
\hline $\mathrm{BH} * \mathrm{FV} * \mathrm{X}$ & 3 & 5.34 & 1.78 & 7.46 & 0.0001 \\
\hline $\mathrm{PS} * \mathrm{DP} * \mathrm{BH} * \mathrm{FV}$ & 12 & 27.58 & 2.30 & 9.62 & 0.0001 \\
\hline $\mathrm{PS} * \mathrm{DP} * \mathrm{BH} * \mathrm{X}$ & 12 & 7.19 & 0.60 & 2.51 & 0.0031 \\
\hline $\mathrm{PS} * \mathrm{BH} * \mathrm{FV} * \mathrm{X}$ & 3 & 1.24 & 0.41 & 1.73 & 0.1585 \\
\hline $\mathrm{DP} * \mathrm{BH} * \mathrm{FV} * \mathrm{X}$ & 16 & 6.61 & 0.41 & 1.73 & 0.0369 \\
\hline $\mathrm{PS} * \mathrm{DP} * \mathrm{BH} * \mathrm{FV} * \mathrm{X}$ & 16 & 6.20 & 0.39 & 1.62 & 0.0579 \\
\hline Error & 800 & 191.23 & 13.47 & & \\
\hline
\end{tabular}

$\mathrm{R}^{2}=0.92$

$\mathrm{CV}=12.32 \%$

$\mathrm{PS}=$ particle size

$\mathrm{DP}=$ distributor plate angle

$\mathrm{BH}=$ bed height

$\mathrm{FV}=$ fluidization velocity

$\mathrm{X}=$ radial distance from wall

The four variables (sand particle size, bed height, distributor plate angle and fluidizing velocity) had significant effects on the residence time (at 0.0001). The analysis also showed that there were interactions between these variables (at 0.0001 ). The results showed that all the levels of each variable were significantly different from each other at 0.05 percent. However, there were no significant differences between the measure-ments taken at half the radial distance from the central axis of the fluidizing column and those taken at the center.

Regression analyses were also performed on the data as shown in Table 5. The regression equation is as follows:

$$
\begin{aligned}
\mathrm{T}=1.167284 & -0.00957(\mathrm{PS})-0.78082(\mathrm{DP}) \\
& -0.05833(\mathrm{BH})-0.71994(\mathrm{FV}) \\
& +0.00215(\mathrm{PS} \times \mathrm{DP}) \\
& +0.00058(\mathrm{PS} \times \mathrm{BH}) \\
& +0.00555(\mathrm{PS} \times \mathrm{FV}) \\
& +0.02223(\mathrm{DP} \times \mathrm{BH}) \\
& +0.41132(\mathrm{DP} \times \mathrm{FV}) \\
& -0.00008(\mathrm{PS} \times \mathrm{DP} \times \mathrm{BH}) \\
& -0.00115(\mathrm{PS} \times \mathrm{DP} \times \mathrm{FV}) \\
& -0.00032(\mathrm{PS} \times \mathrm{BH} \times \mathrm{FV}) \\
& -0.001147(\mathrm{DP} \times \mathrm{BH} \times \mathrm{FV}) \\
& -0.00004(\mathrm{PS} \times \mathrm{DP} \times \mathrm{FV})
\end{aligned}
$$


Table 4. Mean values of residence time as affected by sand particle size.

\begin{tabular}{clll}
\hline Parameter & $\begin{array}{l}\text { Number of } \\
\text { Observations }\end{array}$ & $\begin{array}{l}\text { Residence } \\
\text { time }(\mathrm{sec})\end{array}$ & Grouping \\
\hline $\begin{array}{c}\text { Particle Size }(\mu \mathrm{m}) \\
536\end{array}$ & 480 & 2.63 & $\mathrm{~A}$ \\
198 & 480 & 2.14 & $\mathrm{~B}$ \\
$\begin{array}{c}\text { Distributor Plate Angle } \\
10^{\circ} \text { convex }\end{array}$ & 192 & 1.73 & $\mathrm{~A}$ \\
$5^{\circ}$ convex & 192 & 2.09 & $\mathrm{~B}$ \\
Flat & 192 & 2.37 & $\mathrm{C}$ \\
$5^{\circ}$ concave & 192 & 2.64 & $\mathrm{D}$ \\
$10^{\circ}$ concave & 192 & 3.10 & $\mathrm{E}$ \\
Bed Height & & & \\
$2.0 \mathrm{D}$ & 240 & 4.06 & $\mathrm{~A}$ \\
$1.5 \mathrm{D}$ & 240 & 2.77 & $\mathrm{~B}$ \\
$1.0 \mathrm{D}$ & 240 & 1.78 & $\mathrm{C}$ \\
$0.5 \mathrm{D}$ & 240 & 0.92 & $\mathrm{D}$ \\
Fluidization Velocity & & & \\
$1.5 \quad \mathrm{U}_{\text {mf }}$ & 480 & 2.69 & $\mathrm{~A}$ \\
$1.75 \mathrm{U}_{\mathrm{mf}}$ & 480 & 2.08 & $\mathrm{~B}$ \\
Injection Distance & & & \\
$0.5 \mathrm{R}$ & 480 & 2.39 & $\mathrm{~A}$ \\
$1.0 \mathrm{R}$ & 480 & 2.38 & $\mathrm{~A}$ \\
\hline
\end{tabular}

Means with same letter are not significantly different at 0.05 percent level

$\mathrm{D}=$ Inner diameter of fluidizing column $(\mathrm{cm})$

$\mathrm{U}_{\mathrm{mf}}=$ Minimum fluidizing velocity $(\mathrm{cm} / \mathrm{s})$

$\mathrm{R}=$ Bed radius $(\mathrm{cm})$
Where:

$\mathrm{T}=$ residence time $(\mathrm{s})$

$\mathrm{PS}=$ sand particle size $(\mu \mathrm{m})$

$\mathrm{BH}=$ bed height $(\mathrm{cm})$

$\mathrm{FV}=$ fluidizing velocity $(\mathrm{cm} / \mathrm{s})$

$\mathrm{DP}=$ Distributor plate angle $\left(^{\circ}\right)$

The correlation coefficient $\left(\mathrm{R}^{2}\right)$ of the regression analysis was lower (0.81) than that of the analysis of variance (0.92) Furthermore, the coefficient of variability of the regression of analysis was higher $(28.69 \%$ than that of the analysis of variance $(12.35 \%)$.

\subsubsection{Effect of Particle Size}

The results showed that longer residence times were observed with coarse sand as compared to those of fine sand. On the average, a residence time of 2.63 seconds and 2.14 seconds were obtained with the coarse and fine sand, respectively. This was due to the differences in bubble velocities caused by different groups of particles. According to Geldart's classification (Geldart, 1986), fine sand $\left(d_{p}=198 \mu \mathrm{m}\right)$ falls within the range of Group (B) particles $(60 \mu \mathrm{m}<$ $\left.\mathrm{d}_{\mathrm{p}}<500 \mu \mathrm{m}\right)$ and coarse sand $\left(\mathrm{d}_{\mathrm{p}}=536 \mu \mathrm{m}\right)$ falls into the boundary between Group (B) and Group (D) particles. With Group (B) particles, most bubbles rise more quickly than the interstitial gas velocity whereas with Group (D) particles all but the largest bubbles rise more slowly than the interstitial gas velocity.

Table 5. Regression Analysis

\begin{tabular}{|c|c|c|c|c|c|}
\hline Variable & DF & Coefficient & ST & $\mathrm{T}$ & $\mathrm{PR}>\mathrm{T}$ \\
\hline Intercept & 1 & 1.16284 & 0.69904 & 1.663 & 0.0965 \\
\hline PS & 1 & -0.00957 & 0.00235 & -4.072 & 0.0001 \\
\hline DP & 4 & -0.78082 & 0.23867 & -3.273 & 0.0011 \\
\hline $\mathrm{BH}$ & 3 & 0.05833 & 0.00371 & 15.735 & 0.0001 \\
\hline FV & 4 & -0.71994 & 0.42274 & -1.703 & 0.0889 \\
\hline PS*DP & 4 & 0.00215 & 0.00059 & 3.640 & 0.0003 \\
\hline PS*BH & 3 & 0.00058 & 0.00005 & 11.476 & 0.0001 \\
\hline PS*FV & 4 & 0.00555 & 0.00143 & 3.253 & 0.0012 \\
\hline $\mathrm{DP} * \mathrm{BH}$ & 12 & 0.02223 & 0.00684 & 3.873 & 0.0001 \\
\hline $\mathrm{DP} * \mathrm{FV}$ & 16 & 0.41132 & 0.14644 & 2.809 & 0.0051 \\
\hline $\mathrm{PS} * \mathrm{DP} * \mathrm{BH}$ & 12 & -0.00008 & 0.00002 & -4.791 & 0.0001 \\
\hline $\mathrm{PS} * \mathrm{DP} * \mathrm{FV}$ & 16 & -0.00115 & 0.00036 & -3.167 & 0.0016 \\
\hline $\mathrm{PS} * \mathrm{BH} * \mathrm{FV}$ & 12 & -0.00032 & 0.00003 & -10.405 & 0.0001 \\
\hline $\mathrm{DP} * \mathrm{BH} * \mathrm{FV}$ & 48 & -0.01147 & 0.00419 & -2.735 & 0.0064 \\
\hline $\mathrm{PS} * \mathrm{DP} * \mathrm{BH} * \mathrm{FV}$ & 48 & 0.00004 & 0.00001 & 3.930 & 0.0001 \\
\hline \\
\hline & \multicolumn{5}{|c|}{$\mathrm{CV}=28.69 \%$} \\
\hline \multicolumn{6}{|c|}{ PS = particle size } \\
\hline \multicolumn{6}{|c|}{$\mathrm{DP}=$ distributor plate angle } \\
\hline \multicolumn{6}{|c|}{$\mathrm{BH}=$ bed height } \\
\hline $\mathrm{FV}=$ fluidizat & & & & & \\
\hline
\end{tabular}


Van Lare et al. (1996) investigated the effect of particle size in bubbling fluidized beds and found that increases in mean particle size lead to decreases in bubble rise velocity, increased bubble coalescence and thus decreased bubble frequency, which all contribute to increased residence time.

Kunii and Levenspiel (1990) reported that bubbles rise the fastest in fluidized beds of fine particle size, and the slowest in beds of large particle size. They reported that in fine sand bubbles rise faster than the gas in the emulsion, whereas coarse sand allows for faster gas travel through the emulsion and slower bubble rising. This is believed to be due to the large void volume in coarse sand allowing for low resistance to gas flow through the emulsion.

Wiman and Almstedt (1998) reported that for a given excess fluidization velocity $\left(\mathrm{U}_{\mathrm{o}}-\mathrm{U}_{\mathrm{mf}}\right)$, the fastest bubble rise velocities occurred with the smallest sand particle size used for a given excess fluidization velocity $\left(\mathrm{U}_{\mathrm{o}}-\mathrm{U}_{\mathrm{mf}}\right)$.

\subsubsection{Effect of Distributor Plate}

The results showed that a decrease in the angle of convex and an increase in the angle of concave decreased the residence time. The average value of the residence time varied from a low of 1.73 seconds for the distributor plates having a $10^{\circ}$ convex profile to a high of 3.10 seconds for the distributor plate having a $10^{\circ}$ concave profile. This is because the bed height at the center increased when using a distributor plate with a concave surface and decreased with using a distributor plate with a convex surface as shown in Fig. 8. A linear relationship between the angle of distributor plate and residence time was recorded as shown in Fig. 9.

Svensson et al. (1996) investigated the influence of air distributor design on the bubble rise velocity and frequency of circulating fluidized bed. They reported that pressure drop across the distributor was the only significant factor affecting the fluidizing regime. Increasing the pressure drop across the distributor lead to increases in bubble size and rise time resulting in reduced residence time.

Gelperin et al. (1982) studied the variation in fluidization along an angled distributor plate and found the minimum fluidization velocity to vary from a minimum value at the site of the lowest bed height (highest point of distributor plate) to a maximum at the site of the greatest bed height (lowest point of the distributor plate). This variation created a gradient in the effective fluidization velocity experienced in different regions of the bed.

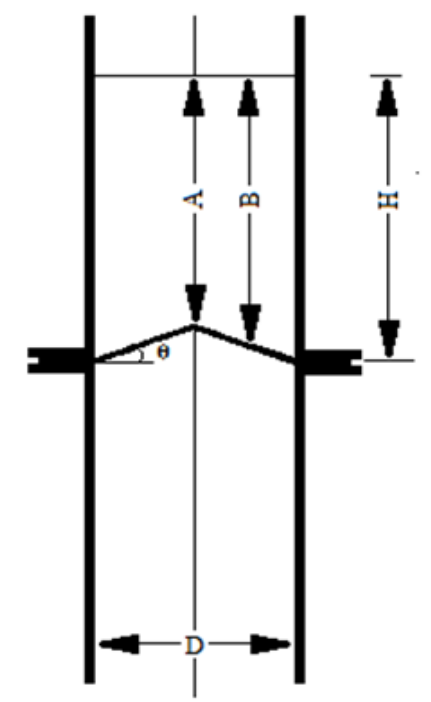

(a) Convex

\begin{tabular}{|c|c|c|}
\hline $\boldsymbol{\theta}$ & $\mathbf{A}$ & $\mathbf{B}$ \\
\hline $\mathbf{5}$ & $\mathrm{H}-1.12 \mathrm{~cm}$ & $\mathrm{H}-0.56 \mathrm{~cm}$ \\
\hline $\mathbf{1 0}$ & $\mathrm{H}-2.24 \mathrm{~cm}$ & $\mathrm{H}-1.12 \mathrm{~cm}$ \\
\hline
\end{tabular}

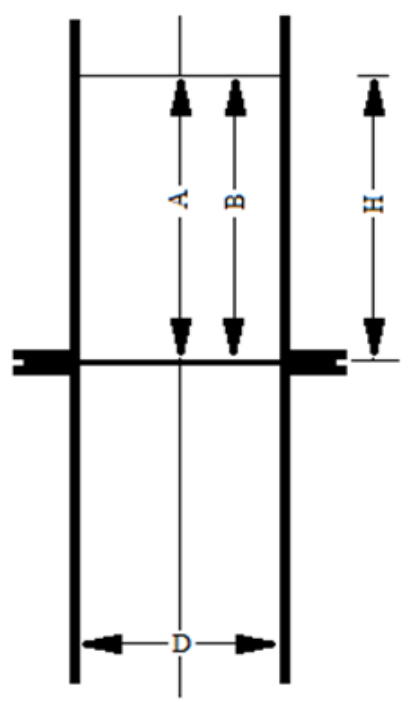

(b) Flat

$\mathbf{A}=\mathbf{B}=\mathbf{H}$

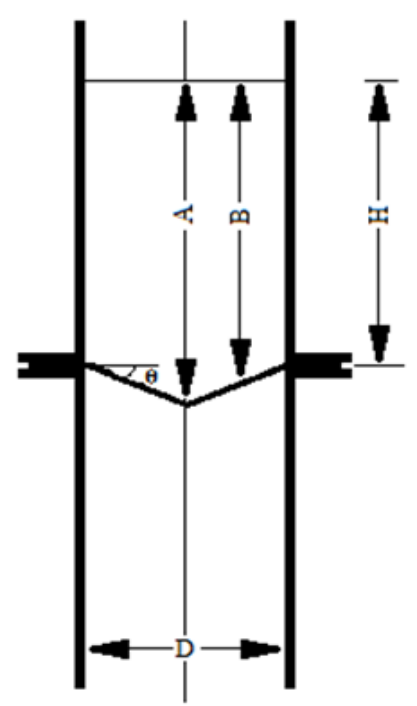

(c) Concave

\begin{tabular}{|l|l|l|}
\hline $\mathbf{\Theta}$ & $\mathbf{A}$ & $\mathbf{B}$ \\
\hline $\mathbf{5}$ & $\mathrm{H}+1.12 \mathrm{~cm}$ & $\mathrm{H}+0.56 \mathrm{~cm}$ \\
\hline $\mathbf{1 0}$ & $\mathrm{H}+2.24 \mathrm{~cm}$ & $\mathrm{H}+1.12 \mathrm{~cm}$ \\
\hline
\end{tabular}

Fig. 8. Effect of distributor plate on the vertical transport of the tracer particles. 


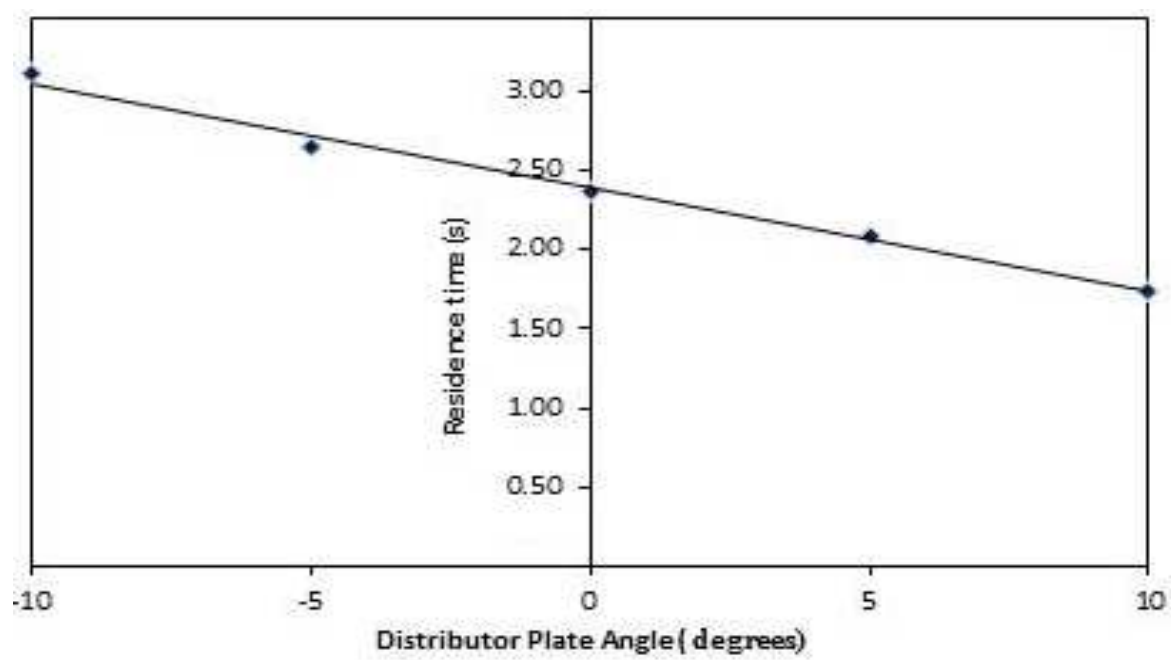

Fig. 9. Effect of distributor plate angle (degrees)

The results obtained in this study showed a decreased residence time in the regions above the peak of the plates and increased residence time above the lowest point of the plates. As the Styrofoam balls were injected near the center of the bed in these experiments, the decreased residence time with the convex plate would be consistent with an increased effective fluidization velocity near the center.

\subsubsection{Effect of Bed Height}

An increase in the bed height (from 0.5 to $2.0 \mathrm{D}$ ) increased the residence time from a low of $0.92 \mathrm{~s}$ to a high of $4.06 \mathrm{~s}$. The variation in the residence time with bed height was also linear as shown in Fig. 10.

Guardiola et al. (1996) reported a decrease in bubble rise velocity with increasing bed height, leading to increased residence time for a given fluidization velocity. Longer rise distances allow for bubble coalescence, creating larger bubbles which rise slower than smaller bubbles due to friction with the column walls.

Van Lare et al. (1996) reported that increasing the bed height did not affect the bubble rise velocity in a fluidized bed but increased the residence time, due to the increased distance to be traveled by the material.

Manya et al. (2006) studied the gasification of dried sewage sludge in a fluidized bed and reported increased residence time from 1.2 to 2.3 seconds when the bed height was increased from 150 to $300 \mathrm{~mm}$.

\subsubsection{Effect of Fluidization Velocity}

The Styrofoam balls were carried up in the bed by the bubbles and the residence time was primarily the function of bubble velocity and frequency. The mean value of the residence time decreased as the fluidizing velocity was increased. The bubble diameter also increased when fluidization velocity was increased.

Van Lare et al. (1996) stated that bubble velocity generally increased with increases in the fluidization velocity. Therefore, the increase in fluidization velocity resulted in higher bubble velocities which consequently gave lower residence times.

Guardiola et al. (1996) reported increased bubble size, velocity and frequency with increased fluidization velocity. Al-Zahrani and Daous (1996) reported a linear relationship between fluidization velocity and bubble rise velocity.

The percent bed height expansion was affected by the fluidizing velocity. For a given bed height, the higher fluidization velocities lead to greater expansions of the bed material. Taghipour et al. (2005) and Al-Zahrani and Daous (1996) reported an approximately linear relationship between bed expansion and fluidization velocity.

\subsubsection{Effect of Radial Position}

The position of the injector did not have any significant effect on the residence time. The measurements were taken only for two positions of the injector; one was at the center of the bed whereas the other was halfway between the center and the wall of the bed. Thus, two points were not enough to conclude on the effect of the injector position on the residence time. However, it was observed that the sand particles descended in the bubble free regions resulting in an overall convective circulation and rapid localized mixing. 


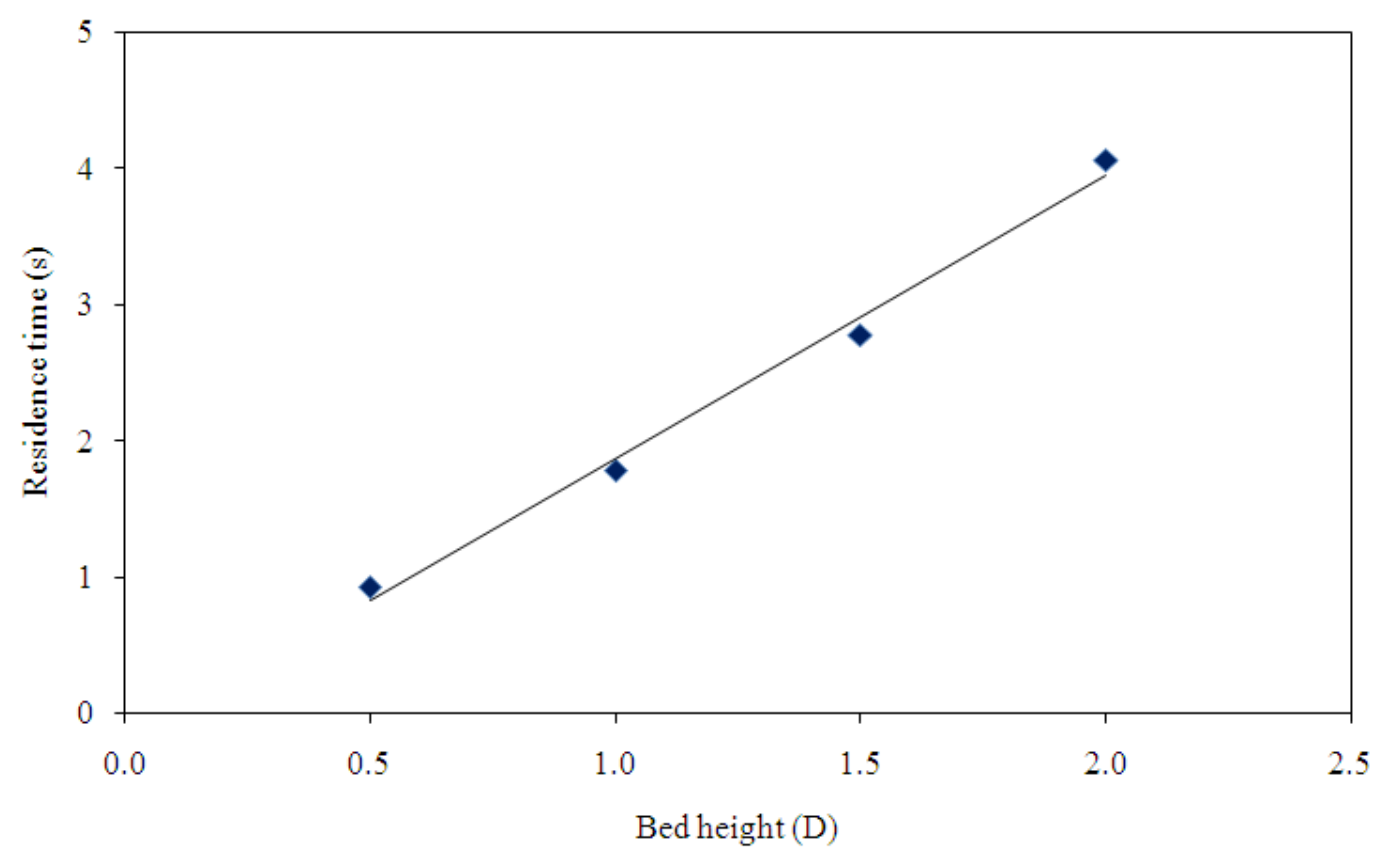

Fig. 10. Effect of distributor angle on the residence time.

\section{CONCLUSIONS}

The sand particle size, distributor plate shape and angle, bed height and fluidizing velocity on particle mixing and residence time in the fluidized bed reactor. Greater values of the residence time were obtained with course sand whereas lower values were obtained with fine sand. An increase in the angle of convex or a decrease in the angle of a concave of the distributor plate resulted in an increase in the residence time. Both the concave and convex distributor plates achieved vertical upward and downward movements of the bed material resulting in continuous bed material turnover and, thus, good mixing. However, the concave plate achieved longer residence time which results in better conversion efficiency. To improve the mixing properties of the binary mixture, which has great tendency for segregation due to density differences, an angled distributor plate (concave or convex) should be used. Considerable increases in the residence time were recorded with increases in the bed height. Increasing the fluidizing velocity decreased the residence time due to the increase in the bubble velocity. However, since the conversion efficiency is affected by the degree of mixing, it will also be improved by increasing the fluidization velocity. A velocity above $1.50 \mathrm{U}_{\mathrm{mf}}$ is recommended for better fluidization and improved mixing.

\section{ACKNOWLEDGEMENTS}

This research was funded by the Natural Science and Engineering Research Council (NSERC) of Canada.

\section{REFERENCES}

Al-Zahrani, A. A. and A. Daous, 1996. Bed expansion and average bubble rise velocity in a gas-solid fluidized bed. Powder Technology, 87: 255-257. DOI: 10.1016/0032-5910(96)03095-1.

Bonniol, F., C. Sierra, R. Occelli and L. Tadrist, 2009. Similarity in dense gas-solid fluidized bed, influence of the distributor and the air-plenum. Powder Technology, 189: 14-24. DOI: 10.1016/j.powtec.2008.05.011.

Chyang, C.S., K. Lieu and S. S. Hong, 2008. The effect of distributor design on gas dispersion in a bubbling fluidized bed. Journal of the Chinese Institute of Chemical Engineers, 39: 665-692. DOI: 10.1016/j.jcice.2008.05.011.

Ergudenler, A. and A. E. Ghaly, 1992. Quality of gas produced from wheat straw in a dual distributor fluidized bed gasifier. Biomass and Bioenergy, 3: 419-430. DOI: 10.1016/0961-9534(92)90038-R. 
Ergudenler, A. and A. E. Ghaly, 1993. Agglomeration of alumina sand in a fluidized bed straw gasified at elevated temperatures. Bioresource Technology, 48: 259-268. DOI: 10.1016/0960-8524(93)90039-E

Ergudenler, A., A. E. Ghaly, F. Hamdullahpur and A. M. Al-Taweel, 1997. Mathematical modelling of a fluidized bed straw gasifier: Part II- Model sensitivity. Energy Sources, 19: 1085-1098. DOI: 10.1080/00908319708908909.

Geldart, D., 1986. Gas Fluidization Technology. 1st Edn., John Wiley and Sons, New York, ISBN: 0471908061.

Gelperin, N.I., V.G. Ainshtein, L.D. Pogorelaya, V.A. Lyamkin and N.I. Terekhow et al., 1982. Limits of stable fluidization regimes in vessel with inclined gas distributor grid. Chemistry and Technology of Fuels and Oils, 18: 20-24. DOI: 10.1007/BF00727482.

Gibilaro, L.G., 2001. Fluidization Dynamics. 1st Edn., Elsevier Butter Worth-Hainemann. Waltham, MA, U.S.A. ISBN: 9780750650038.

Goyal, H.B., D. Seal and R.C. Saxena, 2008. Bio-fuels from thermochemical conversion of renewable resources: A review. Renewable and Sustainable Energy Reviews, 12: 504-517. DOI: 10.1016/j.rser.2006.07.014.

Guardiola, J., V. Rojo and G. Ramos, 1996. Influence of particle size, fluidization velocity and relative humidity on fluidized bed electrostatics. Journal of Electrostatics, 37: 1-20. DOI: 10.1016/0304-3886(96)00002-2.

Khan, A.A., W. deJong, P.J. Jansens and H. Spliethoff, 2009. Biomass combustion in fluidized bed boilers: Potential problems and remedies. Fuel Processing $\begin{array}{lll}\text { Technology, } & 90: & \text { 21-50. }\end{array}$ 10.1016/j.fuproc.2008.07.012.

Kunii, D. and O. Levenspiel, 1990. Fluidized reactor models. 1. For bubbling beds of fine, intermediate and large particles. 2. for the lean phase: freeboard and fast fluidization. Industrial and Engineering Chemistry Research, 29: 1336-1234. DOI: 10.1021/ie00103a002.

Mansaray, K. G. and A. E. Ghaly, 1999. Air gasification of rice husk in a dual distributor type fluidized bed reactor. Energy Sources, 2: 867-882. DOI: 10.1016/S0961-9534(99)00046-X.

Manya, J.J., J.L. Sanchez, J. Abrego, A. Gonzalo and J. Arauzo, 2006. Influence of gas residence time and air ratio on the air gasification of dried sewage sludge in a bubbling fluidized bed. Fuel, 85: 2027-2033. DOI: 10.1016/j.fuel.2006.04.008.
McCartney, D.H., H.C. Block, Dubeski, P.L. and A.J. Ohama. 2006. Review: The composition and availability of straw and chaff from small grain cereals for beef cattle in western Canada. Canadian Journal of Animal Science, 86: 443-455.

Muller, C.R., J.F. Davidson, J.S. Dennis and A.N. Hayhurst, 2007. A study of the motion and eruption of a bubble at the surface of a two-dimensional fluidized bed using Particle Image Velocimetry (PIV). Industrial and Engineering Chemistry Research, 46: 1642-1652. DOI: 10.1021/IE0611397.

Naik, S., V.V. Goud, P.K. Rout, K. Jacobson and A.K. Dalai, 2010. Characterization of Canadian biomass for alternative renewable biofuel. Renewable Energy, 35: 1624-1631. DOI: 10.1016/j.rene.2009.08.033.

Nemtsow, D.A. and A. Zabaniotou, 2008. Mathematical modelling and simulation approaches of agricultural residues air gasification in a bubbling fluidized bed reactor. Chemical Engineering Journal, 143 : $10-31$ DOI: 10.1016/j.cej.2008.01.023.

Nienow, A.W., P.N. Rowe and L.Y.L. Cheung, 1978. A quantitative analysis of the mixing of two segregating powders of different density in a gas fluidized bed. Powder Technology, 20: 89-97. DOI: 10.1016.0032-5910(78)80013-8.

Rowe, P.N. and A.W. Nienow, 1976. Particles mixing and segregation in gas fluidized beds: a review. Powder Technology, 15: 141-147. DOI: 10.1016/0032-5910(76)80042-3.

Sathiyamoorthy, D. and R.C. Sridhar, 1979. Multi orifice plate distributor in gas fluidized beds- A model for design of distributors. Powder Technology, 24: 215-223. DOI: 10.1016/0032-5910(79)87038-2.

Stein, M., Y.L. Ding, J.P.K Seville and D.J. Parker, 2000. Solids motion in bubbling gas fluidized beds. Chemical Engineering Science, 55: 5219-5300. DOI: 10.1016/S0009-2509(00)00177-9.

Surisetty, V.R., J. Kozinski and A.K. Dalai, 2012. Biomass, availability in Canada, and gasification: an overview. Biomass Conversion and Biorefinery, 2: 73-85. DOI: 10.1007/s13399-011-0024-0.

Svensson, A., F. Johnsson and B. Leckner, 1996. Fluidization regimes in non-slugging fluidized beds: The influence of pressure drop across the air distributor. Powder Technology, 86: 299-312. DOI: 10.1016/0032-5910(95)03055-7.

Taghipour, F., N. Ellis and C. Wong, 2005. Experimental and computational study of gas-solid fluidized bed hydrodynamics. Chemical Engineering Science, 60: 6857-6867. DOI: 10.1016/j.ces.2005.05.044. 
Van Lare, C.E.J., H.W. Piepers, J.N. Schoonderbeek and D. Thoenes, 1996. Investigation on bubble characteristics in a gas fluidized bed. Chemical Engineering Science, 55: 829-841. DOI: 10.1016/S0009-2509(96)00442-3.

Werther, J., 1978. Influence of the distributor design on bubble characteristics in large diameter gas fluidized beds. In Fluidization: Proceedings of the Second Engineering Foundation Conference, Eds. Davidson, J.F., and D. L. Kearins, pp. 7-11. ISBN: 0521219434

Wiman, J. and A.E. Almsedt, 1998. Influence of pressure, fluidization velocity and particle size on the hydrodynamics of a freely bubbling fluidized bed. Chemical Engineering Science, 53(12): 2167-2176. DOI: 10.1016/S0009-2509(98)00056-6.
Wood, S.M. and D.B. Layzell, 2003. A Canadian Biomass Inventory: Feedstocks for a Bio-based Economy. BIOCAP Canada Foundation, Kingston, Ont.

Yoshida, K., H. Kameyama and F. Shimizu, 1980. Mechanism of particle mixing and segregating in gas fluidized beds. In Fluidization, Grace, J.R. and J.M. Matsen, (Eds.). Plenum Press, ISBN: 0306404583.

Zeng, X., Y. Mia and L. Ma, 2007. Utilization of straw in biomass energy in China. Renewable and Sustainable Energy Reviews, 11: 976-987. DOI: 10.1016/j.rser.2005.10.003. 